\title{
Organ irradiation and combination chemotherapy in treatment of acute lymphocytic leukaemia in children
}

\author{
P. LANZKOWSKY, A. SHENDE, I. ARAL, and G. SALUJA
}

From the Division of Pediatric Hematology-Oncology, Department of Pediatrics and Division of Radiation Therapy, Department of Radiology, Long Island Jewish-Hillside Medical Centre, New Hyde Park, New York; and Department of Pediatrics and Radiology, School of Medicine, Health Sciences Center, State University of New York at Stony Brook

\begin{abstract}
Lanzkowsky, P., Shende, A., Aral, I., Saluja, G. (1975). Archives of Disease in Childhood, 50, 685. Organ irradiation and combination chemotherapy in treatment of acute lymphocytic leukaemia in children. A total of 30 consecutive children with acute lymphocytic leukaemia (ALL) were treated from June 1971 until December 1974. Remission was induced with the use of vincristine and prednisone. After induction of remission, cranial irradiation and intrathecal methotrexate were given. Then the liver, spleen, and kidney were irradiated and 6-mercaptopurine, cyclophosphamide, and methotrexate were administered during the maintenance phase. Pulsed doses of vincristine and prednisone were administered at 10- to 12-week intervals. The patients were subdivided into two groups based on their initial white blood cell (WBC) counts: a standard risk group with an initial WBC count of $<25000 / \mathrm{mm}^{3}\left(25 \times 10^{9} / 1\right)$ and a high risk group with an initial WBC count $>25000 / \mathrm{mm}^{3}\left(25 \times 10^{9} / \mathrm{l}\right)$. Of the 30 children entered in this study one standard risk patient died in the induction phase before attaining remission. Analysis of the results is therefore based on the remaining 29 patients, 22 standard risk and 7 high risk patients, who attained complete remission. Survival rates in continuous remission were found to be $43 \%$ of the high risk group, $88 \%$ for the standard risk group, and $77 \%$ for the combined group. Analysis of the data indicates that this therapy is unsatisfactory in high risk ALL. The results to date of this therapy for standard risk are sufficiently encouraging to continue its use in this subgroup of patients.
\end{abstract}

Modern therapy of acute lymphocytic leukaemia (ALL) in children attempts to achieve prolonged continuous remission. Effective use of multiple agent combination therapy for the control of systemic disease has increased the incidence and prolonged the duration of the survival of children with acute lymphoblastic leukaemia. Prolongation of survival is the chief cause for the increased incidence of central nervous system (CNS) leukaemia, and this has led to the realization of the importance of preventing CNS infiltration (Evans, Gilbert, and Zandstra, 1970). For this reason, prophylactic cranial irradiation and intrathecal methotrexate (MTX) or craniospinal irradiation are being used routinely in the management of this

Received 18 March 1975. disease. The results of these programmes in welldesigned controlled studies have been shown to be superior to chemotherapy alone (Aur et al., 1971; Aur et al., 1972; Holland and Glidewell, 1972). The rationale for this therapy is to eradicate clinically undetectable leukaemic cells in the CNS early in the disease process since once clinically detectable CNS disease develops even intensive therapy is unsuccessful in eradicating it.

During the past decade there have been many reports (Table I) of the presence of extramedullary leukaemic foci in patients with acute leukaemia in complete clinical remission (Nies et al., 1965; Mathé et al., 1966; Sharp et al., 1967; Simone, Holland, and Johnson, 1972). Early recurrence has been attributed to the persistence of extramedullary foci which was not eradicated by in- 
Persistence of extramedullary leukaemia during remission

\begin{tabular}{|c|c|c|c|c|c|c|c|c|c|c|c|}
\hline \multirow[t]{2}{*}{ Investigators } & \multicolumn{2}{|c|}{$\begin{array}{c}\text { No. of } \\
\text { patients } \\
\text { in remission }\end{array}$} & \multirow{2}{*}{$\begin{array}{l}\text { No. } \\
\text { with extra } \\
\text { medullary } \\
\text { leukaemia }\end{array}$} & \multicolumn{7}{|c|}{$\begin{array}{l}\text { Frequency of extramedullary } \\
\text { leukaemic sites in remission }\end{array}$} & \multirow{2}{*}{$\begin{array}{l}\text { Duration } \\
\text { of } \\
\text { remission }\end{array}$} \\
\hline & ALL & ANL & & Lung & Spleen & Liver & GI tract & CNS & Kidney & Gonads & \\
\hline $\begin{array}{l}\text { Nies et al. }(1965) \\
\text { Mathé et al. }(1966) \\
\text { Sharp et al. }(1967) \\
\text { Simone et al. }(1972)\end{array}$ & $\begin{array}{l}11 \\
26 \\
10 \\
26\end{array}$ & $\begin{array}{l}4 \\
5 \\
- \\
-\end{array}$ & $\begin{array}{r}10 \\
9 \\
4 \\
8\end{array}$ & $\begin{array}{l}2 \\
- \\
\overline{0}\end{array}$ & $\begin{array}{l}- \\
\overline{5}\end{array}$ & $\begin{array}{l}5 \\
4 \\
2 \\
1\end{array}$ & $\begin{array}{l}4 \\
- \\
- \\
0\end{array}$ & $\begin{array}{l}2 \\
4 \\
- \\
3\end{array}$ & $\begin{array}{l}6 \\
2 \\
2 \\
2\end{array}$ & $\begin{array}{l}3 \\
1 \\
- \\
1\end{array}$ & $\begin{array}{c}1-215 \mathrm{~d} \\
- \\
- \\
1-21 \mathrm{~m}\end{array}$ \\
\hline Total & 73 & 9 & 31 & 2 & 5 & 12 & 4 & 9 & 12 & 5 & \\
\hline
\end{tabular}

ALL, acute lymphocytic leukaemia; ANL, acute nonlymphocytic leukaemia.

creasing the intensity of chemotherapy (Mathé et al., 1966). These reports prompted us to add irradiation to the organs with the highest incidence of leukaemic infiltration, namely, the liver, spleen, and kidneys, to eradicate clinically occult foci of leukaemic cells in these organs. In addition to organ irradiation, prophylactic CNS therapy and combination chemotherapy, as described previously (Aur et al., 1971; Aur et al., 1972), was administered.

\section{Materials and methods}

An outline of treatment is illustrated in Table II.

Phase I (induction of remission). Remission was induced with the use of vincristine (VCR) $1.5 \mathrm{mg} / \mathrm{m}^{2}$ intravenous weekly for 5 weeks and prednisone (Pred) $40 \mathrm{mg} / \mathrm{m}^{2}$ orally daily in two to three divided doses for

TABLE II

Treatment protocol

Phase I (induction of remission)

(a) Vincristine (VCR) $1.5 \mathrm{mg} / \mathrm{m}^{2}$ intravenously weekly $\times 5$

(b) Prednisone (Pred) $40 \mathrm{mg} / \mathrm{m}^{2}$ orally daily $\times 4 \mathrm{w}$

Phase II (maintenance of remission)

(1) Organ irradiation (local therapy)

(a) CNS therapy:

Started within $1 \mathrm{w}$ of remission

Cranial irradiation: $<2$ yr of age, 200 rads daily $\times 9$

$>2$ yr of age, 200 rads daily $\times 12$

Intrathecal methotrexate (IT-MTX), $12 \mathrm{mg} / \mathrm{m}^{2}$ twice weekly $\times 5$ doses

(b) Right part of liver and right kidney irradiation:

Started $1 \mathrm{w}$ after completion of CNS therapy, 120 rads daily $\times 10$

(c) Left part of the liver, spleen, and left kidney irridiation:

Started $4 \mathrm{w}$ after completion of right liver and right kidney irradiation, 120 rads daily $\times 10$

(2) Continuation chemotherapy (systemic therapy)

(a) Maintenance therapy:

6-Mercaptopurine (6 MP), $50 \mathrm{mg} / \mathrm{m}^{2}$ orally daily

Methotrexate (MTX), $20 \mathrm{mg} / \mathrm{m}^{2}$ orally weekly

Cyclophosphamide (CPM), $200 \mathrm{mg} / \mathrm{m}^{2}$ orally weekly

6 MP started within $1 \mathrm{w}$ of remission

CPM and MTX started after completion of IT-MTX

(b) Pulsed therapy: administered at 10 to $12 \mathrm{w}$ intervals VCR, $1.5 \mathrm{mg} / \mathrm{m}^{2}$ weekly intravenously $\times 3$

Pred, $40 \mathrm{mg} / \mathrm{m}^{2}$ daily orally $\times 2 \mathrm{w}$
4 weeks. At the end of therapy a bone marrow examination was performed. If it contained less than $5 \%$ leukaemic cells with adequate cellularity, the subject was considered to be in remission and phase II of treatment was instituted. If remission was not obtained, treatment was continued for an additional 2 weeks. L-asparaginase or daunorubicin was administered to any patient who failed to attain a remission after the use of vincristine and prednisone.

Phase II (maintenance of remission). This consisted of (a) organ irradiation and (b) continuous antileukaemic chemotherapy.

(a) Organ irradiation (local therapy). Within one week of attaining remission, prophylactic therapy to the CNS was given to patients under 2 years of age as 1800 rads in 9 treatments, and to those over 2 years as 2400 rads in 12 treatments. The cranium was irradiated through opposing lateral ports using a cobalt-60 unit. In addition, methotrexate was adminstered intrathecally in doses of $12 \mathrm{mg} / \mathrm{m}^{2}$ twice weekly for 5 doses during cranial irradiation treatment. 4 of our early patients received irradiation to the entire craniospinal axis in doses of 2400 rads and received no intrathecal MTX.

A week after completion of prophylactic CNS therapy, the right part of the liver and right kidney were irradiated with a total dose of 1200 rads in 10 divided treatments through two opposing ports. 4 weeks thereafter the left part of the liver, the spleen, and left kidney were irradiated in the same manner. The spinal column was shielded during irradiation.

(b) Continuation chemotherapy (systemic therapy). Continuation therapy with antileukaemic drugs given orally consisted of 6 -mercaptopurine (6MP) $50 \mathrm{mg} / \mathrm{m}^{2}$ daily, methotrexate (MTX) $20 \mathrm{mg} / \mathrm{m}^{2}$ weekly, and cyclophosphamide (CPM) $200 \mathrm{mg} / \mathrm{m}^{2}$ weekly. $6 \mathrm{MP}$ was instituted as soon as bone marrow remission was achieved and prednisone was tapered. Oral MTX and CPM were instituted one week after the last dose of IT-MTX and were administered together weekly.

Pulsed doses of VCR $1.5 \mathrm{mg} / \mathrm{m}^{2}$ weekly intravenously for 2 weeks and Pred $40 \mathrm{mg} / \mathrm{m}^{2}$ daily orally for 2 weeks were administered every $10-12$ weeks. 
Laboratory studies and management of therapy. At the time of entry onto the protocol investigations carried out were complete blood count, bone marrow examination, determination of liver enzymes, alkaline phosphatase, uric acid, calcium, phosphorus, creatinine, blood urea nitrogen, glucose, serum electrolytes, urinalysis, spinal fluid analysis (for protein, glucose, cell count, and culture); $x$-ray examination of skeleton and chest, and an intravenous pyelogram. Cultures of blood, nose, throat, and urine were made as indicated.

During phase I complete blood counts were obtained weekly. At the end of this phase a bone marrow examination was repeated. During phase II, spinal fluid analysis was performed for protein, glucose, cell count, and culture every time MTX was given intrathecally. Complete blood counts were performed weekly for the first several months and thereafter at 1- to 2-week intervals. Before irradiation to the liver and right kidney and the spleen and left kidney, liver chemistries, kidney function tests, and urinalyses were performed. Irradiation to these organs was done only when the uric acid level was $<8 \mathrm{mg} / \mathrm{dl}$, SGOT $<80$ units $/$, blood urea nitrogen $<20 \mathrm{mg} / \mathrm{dl}$, and urinalysis normal. Splenic irradiation was done only when the total white blood cell count was $>1500 / \mathrm{mm}^{3}\left(1.5 \times 10^{9} / 1\right)$ and platelet count was $>50000 / \mathrm{mm}^{3}\left(50 \times 10^{9} / 1\right)$. Bone marrow examinations were performed at 10 to 12 -week intervals before administering the pulsed doses of VCR and Pred.

Chemotherapy was administered in maximum tolerated dosages. As far as possible total white cell counts were maintained between the range of $2000-4000 / \mathrm{mm}^{3}$ $\left(2-4 \times 10^{9} / 1\right)$ and when the counts were $<2000 / \mathrm{mm}^{3}$ $\left(2 \times 10^{9} / 1\right)$ therapy was omitted. During a febrile illness (temperature $>38 \cdot 3^{\circ} \mathrm{C}$ for more than 2 days) therapy was stopped and then resumed 2 days after returning to normal. During upper respiratory tract infection, presumed to be viral in nature, only $6 \mathrm{MP}$ was given.

\section{Patient characteristics.}

Between June 1971 and December 1974 a total of 30 consecutive children with acute lymphocytic leukaemia were treated with a regimen of chemotherapy and sanctuary organ irradiation in the Divisions of Pediatric Hematology-Oncology and Radiation Therapy at Long Island Jewish-Hillside Medical Center. There was no patient selection. 28 patients had clear-cut morphology of acute lymphoblastic leukaemia and the remaining 2 were classified as acute undifferentiated leukaemia (AUL). The patients, 16 males and 14 females, ranged in age from 10 months to 15 years 9 months. 29 were white and one was black. One patient died in the induction phase before achieving remission and hence was not included in the statistical analysis done. at the end of December 1974.

One child had Down's syndrome and ventricular septal defect. Diagnosis and repair of an H-type tracheo-oesophageal fistula was made during phase I of therapy in one 15-month-old infant. The same patient had presented with aplastic anaemia 3 months before the diagnosis of ALL. The patient had achieved temporary remission for a few days without any therapy. 2 male patients had had a naevus sebaceus of Jadassohn (organoid naevus) of the scalp before the diagnosis of ALL was made (Lanzkowsky and Shende, 1975a). One female patient had absent right pectoral muscles in association with a large haemangioma on the left forearm (Lanzkowsky, 1975). One patient had haemangioma in the cervical region. One female presented with a subcutaenous leukaemic nodule over the forehead.

Initial total white blood cell counts varied from 2100-204 000/. $\left.\mathrm{mm}^{3} 2 \cdot 1-204 \cdot 0 \times 10^{9} / 1\right)$. No correlation was found between visceromegaly and the level of the white cell count (Lanzkowsky and Shende, 1975b). None of the patients had evidence of CNS leukaemia at the time of initial diagnosis. Table III tabulates initial clinical findings of the patients.

\section{TABLE III}

Clinical characteristics of patients based on initial findings

\begin{tabular}{|c|c|}
\hline Initial clinical features & No. of patients \\
\hline $\begin{array}{l}\text { Age }(y r) \\
<2 \\
2-5 \\
5-10 \\
>10 \\
\text { Race } \\
\text { White } \\
\text { Black } \\
\text { Sex } \\
\text { Male } \\
\text { Female } \\
\text { Leukaemia Type } \\
\text { ALL } \\
\text { AUL } \\
\text { Liver size (cm) } \\
<5 \\
>-5 \\
\text { Spleen size }\left(\mathrm{cm}^{2}\right) \\
<5 \\
>5 \\
\text { WBC count } / \mathrm{mm}^{3}\left(\times 10^{9} / \mathrm{l}\right) \\
<5 \\
5-25 \\
25-50 \\
>50 \\
\text { Platelet count } / \mathrm{mm}^{3}\left(\times 10^{9} / \mathrm{l}\right) \\
<25 \\
25-50 \\
50-100 \\
>100\end{array}$ & $\begin{array}{r}7 \\
15 \\
5 \\
3 \\
\\
29 \\
1 \\
16 \\
14 \\
28 \\
2 \\
25 \\
5 \\
23 \\
7 \\
7 \\
6 \\
17 \\
4 \\
3 \\
16 \\
6 \\
2\end{array}$ \\
\hline
\end{tabular}

\section{Results}

The results were analysed by life table method analysis for the duration of complete remission ('leukaemia-free survival rate') to measure the effectiveness of maintenance therapy (Cutler and Ederer, 1958). Complete remission was defined as absence of detectable disease in the haemopoietic and extramedullary tissues, including the CNS.

The patients were divided into two groups based on their initial WBC: a standard risk group with an initial WBC count of $<25000 / \mathrm{mm}^{3}\left(25 \times 10^{9} / 1\right)$ 


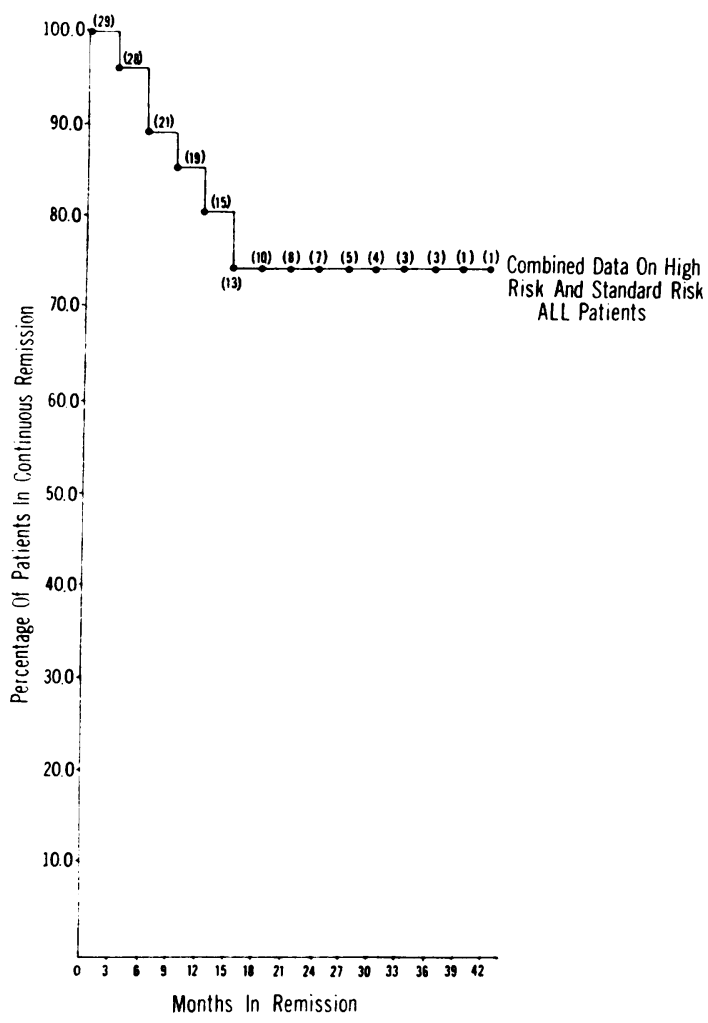

Fig. 1.-Percentage of survival in continuous remission for combined standard risk $\left(W B C<25 \times 10^{9} / l\right)$ and high risk $\left(W B C>25 \times 10^{9} / L\right) A L L$ patients.

and a high risk group with an initial WBC count of $>25000 / \mathrm{mm}^{3} \quad\left(25 \times 10^{9} / 1\right)$. Of the 30 children entered into this study one standard risk patient failed to achieve remission and died during the induction phase. Analysis of the results is therefore based on 29 patients, 22 standard risk and 7 high risk, who attained complete remission. One standard risk patient achieved remission only with L-asparaginase and another with daunorubicin, after failure with VCR and Pred.

Of the 29 patients achieving remission, 6 relapsed. Of these, 5 died and 1 is alive. Of the 6 replapsed patients, 5 manifested a haematological relapse, and 1 simultaneous CNS and haematological relapse. None died while in remission. The overall median duration of complete remission for the entire group was 15 months. The disease-free survival rate of all the patients with a clear-cut diagnosis of acute lymphoblastic leukaemia was $85 \%$. The disease-free survival rate for the 2 patients with AUL, both of whom fell into the high risk group, was found to be $0 \%$ with a median duration of remission of 4 months.

The overall combined (AUL and ALL) diseasefree survival rate was $75 \%$. $43 \%$ for the high risk group and $88 \%$ for the standard risk group. The difference in survival rates between high and standard risk groups was significant, suggesting that this regimen is unsatisfactory in the treatment of high risk groups (Fig. 1 and 2). Three patients have completed 3 years of therapy in continuous complete remission and have been taken off therapy.

Tolerance to chemotherapy. Tolerance to chemotherapy has been satisfactory despite its intensity. Virtually all the patients developed transient leucopenia (WBC $<2000 / \mathrm{mm}^{3}\left(2 \times 10^{9} / 1\right)$ but none became thrombocytopenic (platelets $<100000 / \mathrm{mm}^{3}\left(100 \times 10^{9} / \mathrm{l}\right)$. Mild anemia (Hb $<10 \mathrm{~g} / \mathrm{dl}$ ) was observed in almost all patients.

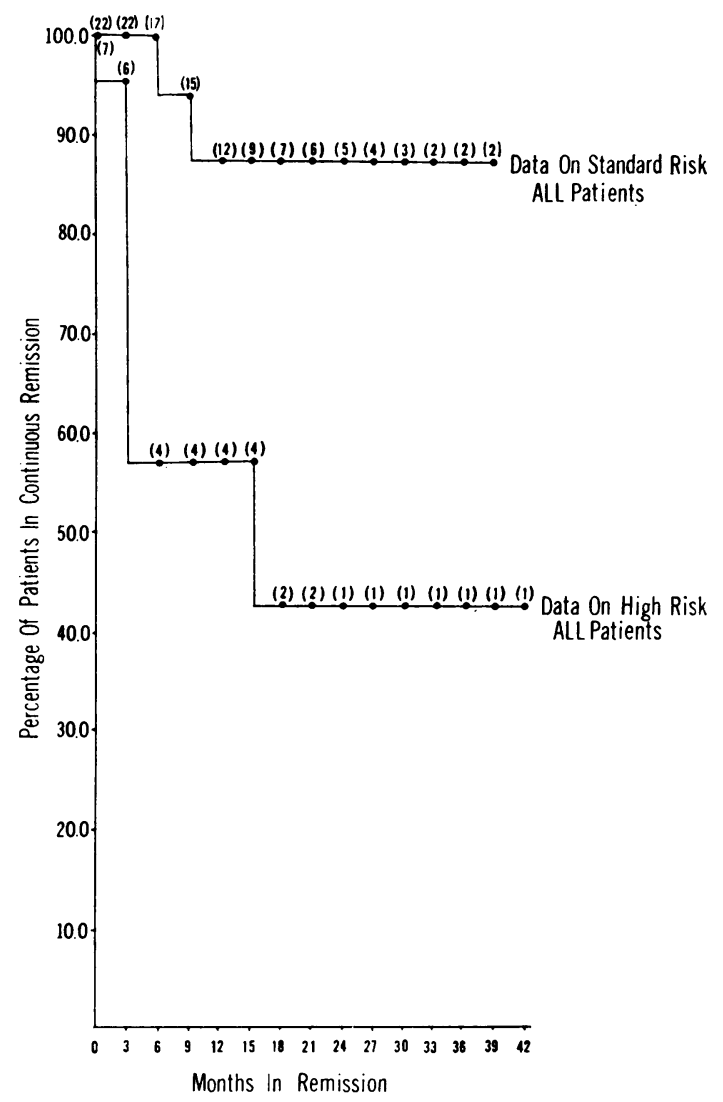

FIG. 2.-Percentage of survival in continuous remission for standard risk (WBC $\left.<25 \times 10^{\circ} / l\right)$ and high risk $\left(W B C>25 \times 10^{\circ} / L\right) A L L$ patients. 
Moderate hypocellularity of bone marrow was observed frequently during the maintenance phase, and megaloblastic changes in the erythroid precursors occurred in every patient.

Side effects of therapy. Vincristine-induced abdominal distension as a result of paralytic ileus was observed in one patient during the maintenance phase. This patient had no further episodes of abdominal ileus once the dose of VCR was halved. During intrathecal MTX administration, 6 patients developed mouth ulcers, 1 developed limping for a few days due to pain in the lower extremities, and 1 developed headache. During oral MTX administration 2 patients developed mouth ulcers. None developed haemorrhagic cystitis during CPM therapy. Severe anaemia was observed in 1 patient after $2 \frac{1}{2}$ years of treatment. This was transient and the bone marrow and blood count returned to normal after temporary cessation of chemotherapy.

Six patients developed excessive drowsiness, for periods of from 1 to 6 weeks, after cranial irradiation. One had fever intermittently for a 2-week period associated with drowsiness after irradiation. Alopecia of 3 to 4 months' duration was observed in all the patients after cranial irradiation. Linear growth retardation was observed in 3 out of the 4 patients who received spinal irradiation. One patient developed transient haematuria towards the end of irradiation therapy to the right kidney, and therefore irradiation to the left kidney and spleen was omitted. One patient, who had received L-asparaginase followed 4 weeks by irradiation to to the liver, developed abnormal liver function tests (SGOT, SPGT, and serum bilirubin) from 1 to 9 weeks after therapy.

\section{Infectious complications.}

Induction phase. Fever (temperature $>39^{\circ} \mathrm{C}$ ) was observed in 24 of the 30 patients during induction. 13 of these had fever of undetermined origin, 4 had documented septicaemia or fungaemia, 6 had bronchopneumonia, and 1 had suppurative lymphadenitis. Of the 4 with septicaemia or fungaemia, 2 had Esch. coli, 1 Pseudomonas, and 1 candidiasis.

Maintenance phase. 10 patients had pyrexia temperature $>39^{\circ} \mathrm{C}$ ) of undetermined origin during maintenance therapy. Individually they had from one to four episodes of pyrexia of undetermined origin. No patient had documented septicaemia or fungaemia during the maintenance phase.
There were 77 episodes of upper respiratory tract infection. The individual patients had from one to eight episodes of upper respiratory infection during the maintenance phase.

Five patients had 8 exposures to chickenpox and one developed the disease. This patient had not received passive immune therapy against chickenpox and made an uneventful recovery. Two patients developed herpes zoster without a history of exposure to chickenpox or herpes zoster, and both made an uneventful recovery. One patient had viral meningitis. The disease was clinically mild and there were no neurological sequaelae.

\section{Discussion}

This protocol was designed with the hope of achieving better disease-free 5-year survival rates in patients with ALL by the addition of sanctuary organ irradiation during maintenance therapy. Organ irradiation was added to the regimen of therapy for ALL, most commonly used and considered to be the most effective. Thus these patients all received currently optimum therapy. Because of the well-known limitations of evaluating different treatment techniques in different series of patients from different institutions, comparison of the results of this study with that of other studies (Pike, 1973; Karon, 1973) has not been attempted.

It is not possible at this stage to predict accurately the 5-year survival results in continuous remission because of the short observation period. However, when the results are calculated by life table method analysis on the basis of the initial WBC counts, it is apparent that patients with WBC counts of $>25000 / \mathrm{mm}^{3}\left(25 \times 10^{9} / 1\right)$ did not do as well as those with counts of $<25000 / \mathrm{mm}^{3}$ $\left(25 \times 10^{9} / 1\right)$. The difference in the patient survival in continuous remission between the two groups was statistically significant. It is our opinion, therefore, that this therapeutic regimen should not be used for the subgroup of patients with initial WBC counts $>25000 / \mathrm{mm}^{3}$ whereas the good results in patients with an initial WBC count of $<25000 / \mathrm{mm}^{3}$ indicate that it is a satisfactory regimen for this group. However, since this regimen has not been shown to date to yield better results than multiple modality chemotherapy without organ irradiation, organ irradiation is not recommended for universal usage until its superiority as a therapeutic modality in ALL has been clearly shown. The effect of organ irradiation on length of survival is the objective of another investigation presently under study.

In the light of the poor results in the high risk group, this study suggests that ALL patients should 
not be treated as a homogeneous group with the same therapy; but patients must be identified as such and treated by a regimen other than the standard therapy in use today. A regimen consisting of multiple drugs used for induction of remission, or for a consolidation phase after induction of remission, or intermittently during the maintenance phase is worthy of trial. Since tolerance of organs to irradiation in combination with intensive chemotherapy is limited, increasing the dose and organ sites of irradiation does not appear to be worthwhile and may be hazardous.

The patients on this protocol did not develop serious complications or fatal infections, or any discernible immediate serious complications of radiotherapy or chemotherapy. They are all leading normal active lives. Despite intensive therapy designed to maintain WBC counts bebetween $2000-4000 / \mathrm{mm}^{3}\left(2-4 \times 10^{9} / 1\right)$, no significant thrombocytopenia with haemorrhagic complications developed.

One patient developed signs of mild hepatotoxicity during irradiation after the use of Lasparaginase, and this should probably be avoided if hepatic irradiation is to follow its use.

Of the 3 patients in whom necropsies were performed, none had evidence of organ damage secondary to irradiation. All 3 patients had leukaemic infiltration of the bone marrow and spleen, 2 had infiltration of liver, lymph nodes, and brain, and 1 had infiltration of the kidney. 1 patient had extensive fungal abscesses in the liver and gastrointestinal tract. One of the patients developed laryngeal stridor during relapse and laryngeal leukaemic infiltrates were found at necropsy. This unusual finding has recently been described in a patient with acute myeloid leukaemia (Ti et al., 1974).

In conclusion, the results of this investigation show that children with ALL who are in the high risk category with WBC counts $>25000 / \mathrm{mm}^{3}$ $\left(25 \times 10^{9} / 1\right)$ should be identified and treated by a regimen other than the standard therapy in use today.
REFERENCES

Aur, R. J. A., Simone, J., Hustu, H. O., Walters, T., Borella, L., Pratt, C., and Pinkel, D. (1971). Central nervous system therapy and combination chemotherapy of childhood lymphocytic leukemia. Blood, 37, 272.

Aur, R. J. A., Simone, J. V., Hustu, H. O., and Verrzosa, M. S. (1972). A comparative study of central nervous system irradiation and intensive chemotherapy early in remission of childhood acute lymphocytic leukemia. Cancer, 29, 381.

Cutler, S. J., and Ederer, F. (1958). Maximum utilization of the life table method in analyzing survival. Fournal of Chronic Diseases, 8, 699.

Evans, A. F., Gilbert, E. S., and Zandstra, R. (1970). The increasing incidence of central nervous system leukemia in children. Cancer, 26, 404.

Holland, J. F., and Glidewell, O. (1972). Oncologists' reply: survival expectancy in acute lymphocytic leukemia. New England fournal of Medicine, 287, 769.

Karon. M. (1973). Problems in the evaluation of long term results. Recent Results in Cancer Research: Nomenclature, p. 113. Methodology and Results of Clinical Trials in Acute Leukaemias, Ed. by G. Mathe, P. Poulliart, and L. Schwarzenberg. Springer-Verlag, New York.

Lanzkowsky, P. (1975). Absence of pectoralis major muscle in association with acute leukaemia. Fournal of Pediatrics, 86, 817.

Lanzkowsky, P., and Shende, A. (1975a). A possible relationship of naevus sebaceus of Jadassohn (organoid naevus) to childhood malignancy. Unpublished.

Lanzkowsky, P., and Shende, A. (1975b). Relationship of liver and spleen size to initial white cell count in acute lymphoblastic leukaemia. Pediatric Research, 9, 389.

Mathé, G., Schwarzenberg, L., Mery, A. M., Cattan, A., Schneider, M., Amiel, J. L., Schlumberger, J. R., Poisson, J., and Wajcner, G. (1966). Extensive histological and cytological survey of patients with acute leukaemia in 'complete remission'. British Medical fournal, 1, 640.

Nies, B. A., Bodey, G. P., Thomas, L. B., Brecher, G., and Freireich, E. J. (1965). The persistence of extramedullary leukemic infiltrates during bone marrow remission of acute leukemia. Blood, 26, 133.

Pike, M. C. (1973). The Analysis of Clinical Trials in Leukaemia. Recent Results in Cancer Research: Nomenclature, Morphology and Results of Clinical Trials in Acute Leukaemias, Vol. 43, p. 126. Ed. by G. Mathé, P. Poulliart, and L. Schwarzenberg. Springer-Verlag, New York.

Sharp, H. L., Nesbit, M. F., D'Angio, G. J., and Krivit, W. (1967). Addition of local radiation after bone marrow remission in acute leukemia in children. Cancer, 20, 1403.

Simone, J. V., Holland, E., and Johnson, W. (1972). Fatalities during remission of childhood leukemia. Blood, 39, 759.

Ti, M., Villafuerte, R., Chase, P. H., and Dosik, H. (1974). Acute leukemia presenting as laryngeal obstruction. Cancer, 34, 427.

Correspondence to Professor P. Lanzkowsky, Department of Pediatrics, Long Island Jewish-Hillside Medical Center, New Hyde Park, New York, 11040, U.S.A. 